---مجلة علوم الرافدين، المجلد 27، العدد 4 / عدد خاص بالمؤتمر العلمي الثالث لعلوم الحياة، ص 88-94، 2018---

دراسة تأثير الإصابة ببكتريا مرض الساق الأسود في إنتاجية البطاطا

\author{
نديم احمد رمضان \\ زهراء سالم المشهداني \\ قسم علوم الحياة/ كلية العلوم/ جامعة الموصل \\ قسم علوم الحياة/ كلية التربية للبنات/ جامعة الموصل
}

(أستلم 2018/6/ 2018 )

\begin{abstract}
الملخص
تمت دراسة قابلية ثمانية اصناف من البطاطا للإصابة بمرض الساق الأسود وكانت جميعها قابلة للإصابة بدرجات متفاوتة

تحت ظروف البيت الزجاجي والحقل باستخدام العدوى الصناعية بمعلق البكتريا بتركيز 10 -4 وحدة مكونة للمستعمرات البكتيرية

لكل مل وكان الصنف دايمونت اكثر الأصناف حساسية للإصابة أما الصنف ديزاري فهو اقلها حساسية. كما تم عزل البكتريا

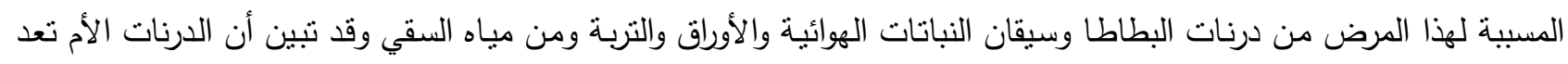

المصدر الأهم لحدوث الإصابة ومن اعراض المرض انخفاض إنتاجية الدرنات وظهور الأوراق المصابة واختلاف أطوال النباتات

نتيجة الإصابة بالبكتريا.

الكلمات الدالة: الدرنات الام، البطاطا، مرض الساق الاسود.
\end{abstract}

\title{
Study of the Effect of Black Leg Disease in Potato Production
}

Zahra S. Al-Mashadani

Nadeem A. Ramadan

Department of Biology/College of Education for Girls Department of Biology/College of Science University of Mosul

\begin{abstract}
The susceptibility of 8 cultivars of potato to infection by black leg disease was studied using artificial inoculation with $10^{-4} \mathrm{CFU} / \mathrm{ml}$ from isolated bacterial. The results showed that all cultivars were susceptible at different levels, under greenhouse and filed condition. Diamond was found to be the most susceptible cultivar to blackleg disease while Desiree was the least susceptible .Different method to treat the blackleg disease. The symptoms were reduction in the production of tubers and the appearance of infected of leaves and the reduction in different plant heights. The bacteria that cause this disease were isolated from potato tubers, shoots, soil and water. The mother tubers were found to be major source of inoculums for blackleg disease.
\end{abstract}

Keywords: Mother tubers، potato، black leg.

المقدمة

تعد البطاطا من اهم محاصيل الخضر في العديد من دول العالم وهي تتبع العائلة الباذنجانية Solanaceae. الني تضم

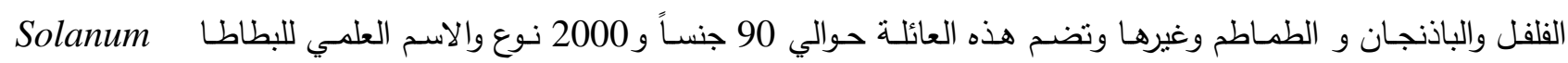

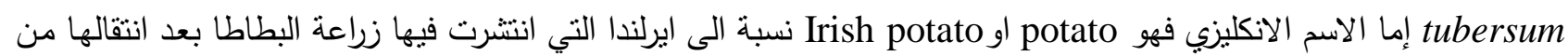
جبال الانديز في امريكا الى اوربا في القرن السـادس عشر ومن هناك انتشرت إلى جميع انحاء العالم (حسن، 1988 ؛ .(Morrenhof, 1998 


$$
\text { زهراء سالم المشهداني و نديم احمد رمضان }
$$

يتراوح عدد اصناف البطاطا في العالم 119 صنفا تزرع في انحاء العالم المختلفة لغاية العام 1997(Haag, 1997). وتتعرض البطاطا الى حوالي 90 مرضاً بكتيرياً وفطرياً و30 مرضاً فايروسياً وهناك أربعون حالة غير اعتبادية غبر معروفة الاسباب. ويعد مرض الساق الأسود المنسبب عن البكتريا Erwinia carotovora var. atroseptica , Erwia chresanthemi البطاطا (DE Boer, 1982) و (رمضان و المشهداني، 2006).

\section{المواد و طرائق العمل}

دراسة إمراضية البكتريا المسبية للمرض تجارب البيت الزجاجي:

تم الحصول على 8 أصناف مختلفة من البطاطا وهي ( تايمت Timate و دايمونت Diamant و ديزاري Desiree وعجيبة Ajiba ولو و مارفونا Marfona و مترال Meyral و ميركال Mirakel). من مركز إباء للبحوث الزراعية

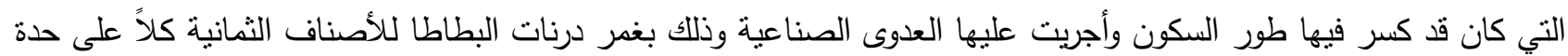

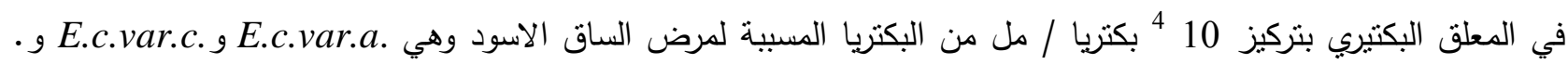
E.ch

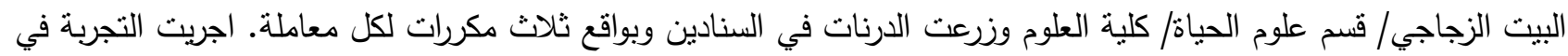
شهر شباط 2000 وقد اخذت البيانات بعد مرور 45 يوم من بدء التلقيح (Prokkola, 1994). تجارب الحقل بعد الحصول على اصناف البطاطا ومعاملتها بالبكتريا كما ورد آنفا، زرعت هذه الدرنات المعاملة، في حقل كلية الزراعة

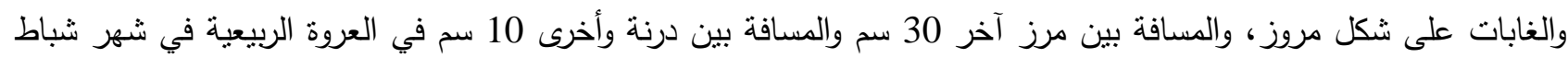

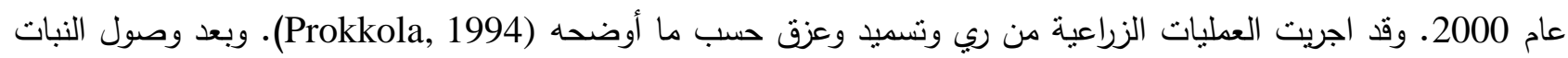
لمرحلة النضج اوققت عمليات السقي قبل اسبوع من القع بعدها نم تسجيل أطوال السيقان وعدد الأوراق المصابة فيها وعدد

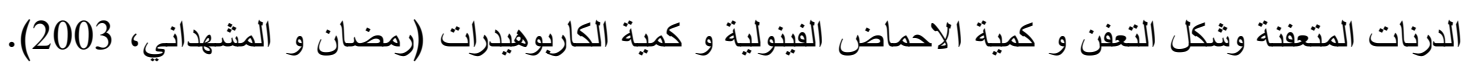
النتائج و المناقشة وكية

دراسة امراضية البكتريا المسببة للمرض تجارب البيث الزجاجي

يوضح (الجدول 1) ان نسبه درنات مصابة تعود للصنف مارفونا المعاملة بالبكتريا E.c.c.a. و. E.ch. وصلت

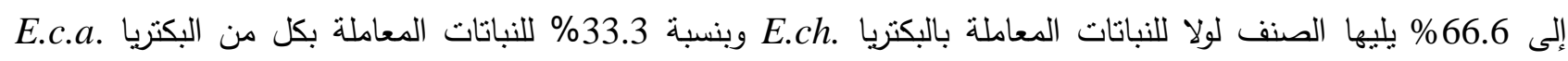
و .E.c.c بينما اعطى الصنف ديزاري و مترال اعلى مقاومة للارنات ولم تصب أية درنة من درنات الصنفين. كما اشتملت الدراسة

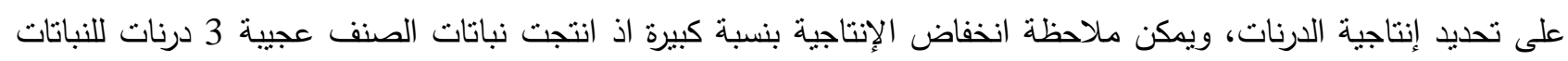
الملقحة بالبكتريا E.c.c. ودرنة واحدة فقط في الصنف دايمونت للنباتات

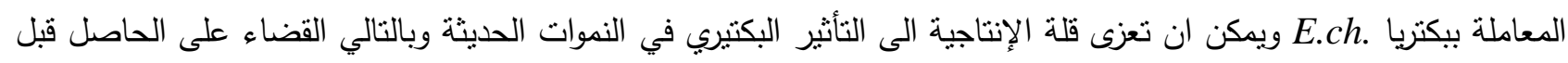

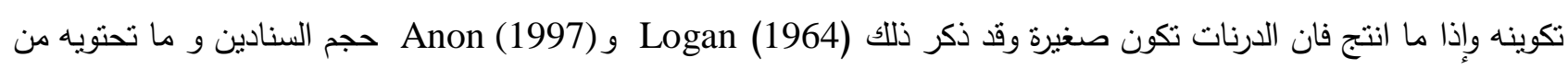
تربة قليلة لا يتيح للنباتات الحيز الواسع للنمو والإنتاج. وان ارتفاع درجة حرارة ورطونية البنان البيت الزجاجي يعدان من العوامل المهمة لتحديد نمو ونشاط البكتريا المسبية للمرض كما أوضح ذلك (1987) Elphinston. 
الجدول 1: النسبة المئوية للارنات المصابة الناتجة من نباتات ملقحة بالبكتريا المزروعة في البيت الزجاجي.

\begin{tabular}{|c|c|c|c|}
\hline \multicolumn{3}{|c|}{ \% للارنات المتعقنة } & \multirow[t]{2}{*}{ الأصناف } \\
\hline E.ch. & E.c.c. & E.c.a. & \\
\hline 0.0 & 0.0 & $* 66.6$ & تايمت \\
\hline 0.0 & 0.0 & 33.3 & دايمونت \\
\hline 0.0 & 0.0 & 0.0 & ديزاري \\
\hline 33.3 & 0.0 & 33.3 & عجيبة \\
\hline 66.6 & 33.3 & 33.3 & لولا \\
\hline 66.6 & 66.6 & 66.6 & مارفونا \\
\hline 0.0 & 0.0 & 0.0 & مترال \\
\hline 0.0 & 0.0 & 33.3 & ميركال \\
\hline
\end{tabular}

"كل رقم يمثل معدل 3 قراءات

ويوضح (الجدول 2) إن الصنف دايمونت أعطى أعلى نسبة أوراق مصابة عند مقارنته بـ 43.33\% و 45.65\%

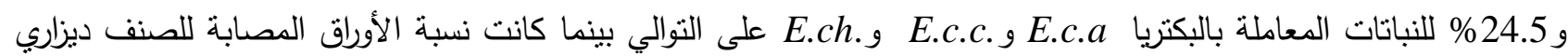
\% و 2.2 \% و 0.ch. E.c.c. E.c.a على التوالي وكانت هناك فروقاً معنوية للصنف ديزاري

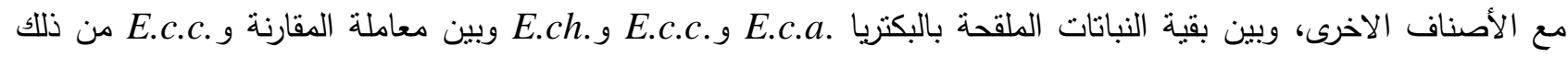

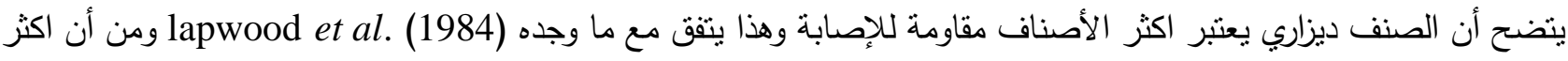
الأصناف مقاومة لإصابة الأوراق هو الصنف ديزاري ويعود سبب اختيار اصابة الأوراق وتحديد نسبها لمعرفة مدى تأثر الاجزاء

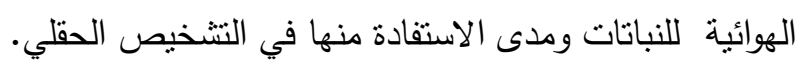

الجدول 2 : النسبة المئوية للأورلق المصابة في النباتات الناتجة من تلقيح الدرنات بالبكتريا المسبية لمرض الساق الأسود

\begin{tabular}{|c|c|c|c|c|c|}
\hline \multirow[b]{2}{*}{ المتوسط } & \multicolumn{3}{|c|}{ البكتريا } & \multirow[b]{2}{*}{ المقارنة } & \multirow[b]{2}{*}{ الاصناف } \\
\hline & E.ch. & E.c.c. & E.c.a. & & \\
\hline 27.86 اب & i 50.0 & 21.56 د-ي & 23.33 د- ي & ${ }^{*} \varepsilon_{-}{ }^{2} 16.65$ & تايمت \\
\hline ¡ 34.1 & 24.5 دهـ وي & 45.65 أب ج & 43.33 أ ب ج & 22.72 دـ _ي & دايمونت \\
\hline 1.31 د د & ز 0.0 & ع 2.22 & ز 0.0 & 3.0 ز ع & ديزاري \\
\hline 13.97 ج & 11.5و ي عز & 23.33 د - ي & 8.1 ز ع ي & 12.93 و ز & عجييه \\
\hline 22.78 ب & 31.95 ب جد & 21.94 د - ي & 21.34 د- ي & 15.87 د_عز & لولا \\
\hline 21.32 ب ج & 22.17 د- ي & 30.0 ج دد هـ & 18.43 د-بي ع & 14.65 هـ-ي عز & مارفونا \\
\hline 21.65 ب ج & 26.1 دهـ و & 31.15 ب ج د & 22.69 د- ي & 6.7 ز ع ي & مترال \\
\hline ¡ 30.65 & ا 46.9 ا ب & ¡ 49.5 & 18.84 د-ي ع & 7.33 ز ع ي & ميركال \\
\hline & $i 26.65$ & $i 28.2$ & 19.5 ب & 12.5 ج & المتوسط \\
\hline
\end{tabular}

*الارقام التي تحمل احرفا متثابهة تدل على عدم وجود فروق معنوية بينها عند مستوى احتمال 0.05 حسب اختبار دنكن افقيا وعموديا.

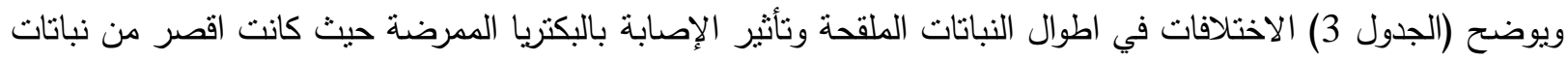

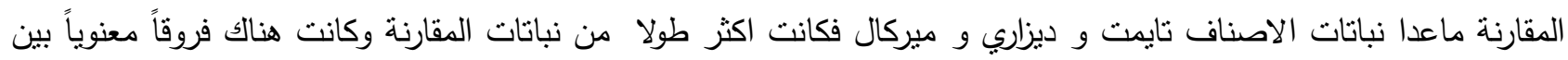


اطوال النباتات المصابة والمقارنة مما يدل على ان هذه الاصناف اكثر مقاومة للإصابة من الاصناف الاخرى التي تؤثر في طول

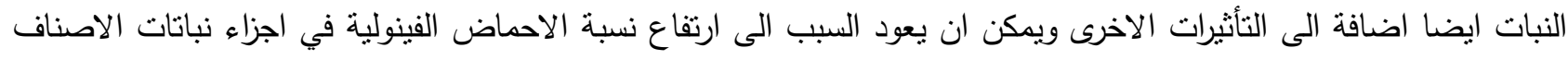
تايمت و ديزاري و ميركال اكثر من بقية الاصناف الاخرى وهي (300 و 388 و 298) مايكرو غرام / غرام على التوالي. وقد لوحظ عدم تلون نهاية الساق بلون حبري او اسود ويمكن ان يعود السبب الى تأخر وقت الزراعة وظهور النباتات في وقت متأخر

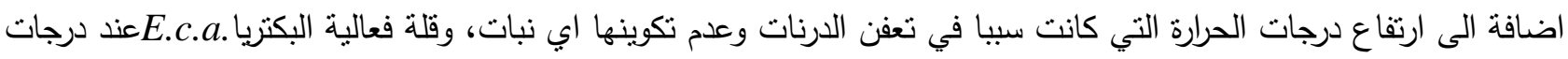

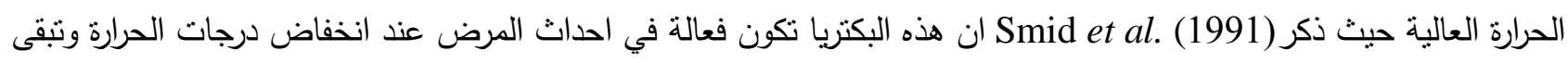

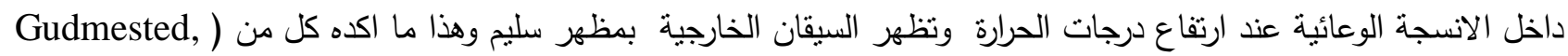

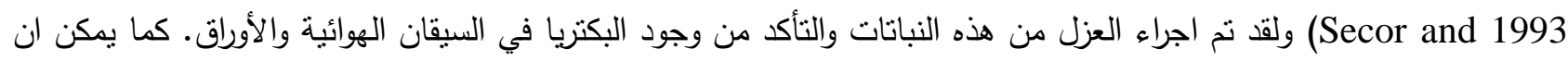

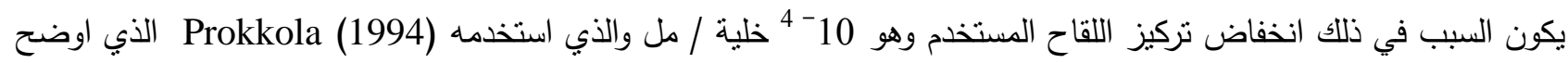
انه من الافضل استخدام التركيز الواطئ؛ لان التركيز العالي يؤدي الى احداث ذبول دبول مباثر .

الجدول 3: تأثير الإصابة بالبكتريا المسببة لمرض الساق الأسود في أطوال السيقان الهوائية للنباتات الملقح درناتها بالبكتريا

\begin{tabular}{|c|c|c|c|c|c|}
\hline \multirow{3}{*}{ المتوسط } & \multicolumn{4}{|c|}{ الطول / سم } & \multirow[t]{3}{*}{ الاصناف } \\
\hline & \multicolumn{3}{|c|}{ البكتريا } & \multirow[t]{2}{*}{ المقارنة } & \\
\hline & E.ch. & E.c.c. & E.c.a. & & \\
\hline 32.5 أ- ج & 34.0 ب - و & 33.0 ب-و & 32.0 ب - و & 31.0 ب- و ** & تايمت \\
\hline 33.0 أ- ج & 28.67 ج-و & 35.0 ب- و & 32.0 ب- و & 36.67 ب - د & دايمونت \\
\hline 32.16 أ - ج & 36.0 أ- هـ & 33.33 ب- و & 34.0 ب- و & 25.33 د-و & ديزاري \\
\hline 32.16 أ - ج & 38.67 أ- ج & 23.0 & 28.0 ج -و & 39.0 أ- ج & عجييه \\
\hline 36.25 أ ب & 31.0 ب-و & 34.0 أ ب & 34.0 ب-و & 37.0 أ- هـ & لولا \\
\hline 37.58 & 25.0 هـ - و & 40.0 أ- ج & 38.0 أ - د & 47.3 & مارفونا \\
\hline 31.5 ب ج & 39.0 أ- ج & 29.0ج - و & 23.0 و و & 35.0 ب - هـ & مترال \\
\hline \multirow[t]{2}{*}{28.5 ج } & 32.0 ب- و & 28.0 ج-و & 29.0 ج -و & 25.0 هـ و & ميركال \\
\hline & 33.0 & 33.0 & 31.3 & أ 34.6 & المتوسط \\
\hline
\end{tabular}

*الأرقام التي تحمل أحرفا متشابهة تدل على عدم وجود فروق معنوية بينها عند مستوى احتمال 0.05 حسب اختبار دنكن أفقيا و عموديا

تجارب الحقل

تمت ملاحظة اعداد الدرنات وأحجامها كما في (الجدول 4). الذي وضح ان تكون 5 درنات في معاملة المقارنة للصنف عجيبة مع النباتات المعاملة بالبكتريا E.c.a. ظهرت درنات صغيره ومتوسطة ولم تظهر درنات كبيرة ويمكن أن يعود سبب ذلك فئك

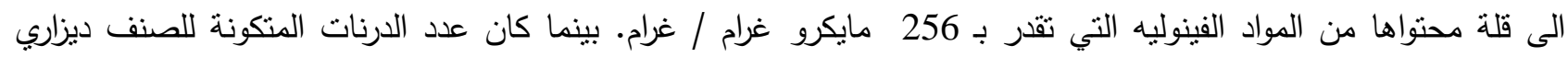

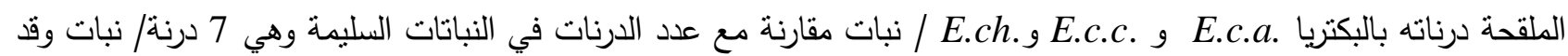

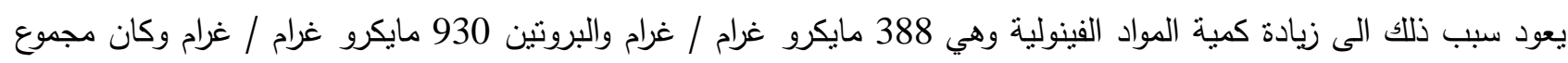

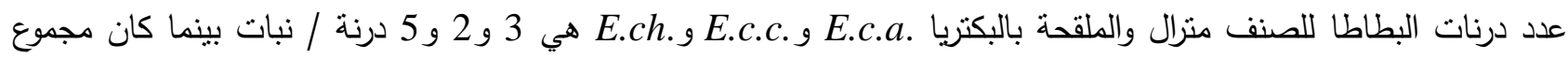


الدرنات المنكونة لمعاملة المقارنة هي 6 درنة، وربما يعود سبب ذلك الى احتواء درنات هذا الصنف على نركيز عال من الكاربوهيدرات الني وصلت الى 7600مايكرو غرام / مل وتعد هذه المواد أولية لعمل الانزيمات التي تمنلكها هذه البكتريا ولقد أثنار

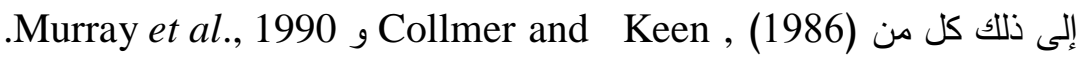

الجدول 4: تأثير تلقيح درنات اصناف البطاطا بالبكتريا المسبية لمرض الساق الأسود في حجم وعدد الدرنات المتكونة في

\begin{tabular}{|c|c|c|c|c|c|c|c|c|c|c|c|c|c|c|c|c|}
\hline & & & & & & & & & & & & \multicolumn{5}{|c|}{ الحقل } \\
\hline \multicolumn{12}{|c|}{ البكتريا } & \multirow{2}{*}{\multicolumn{4}{|c|}{ المقارنة }} & \multirow{3}{*}{ الصنف } \\
\hline \multicolumn{4}{|c|}{ E.ch. } & \multicolumn{4}{|c|}{ E.c.c. } & \multicolumn{4}{|c|}{ E.c.a. } & & & & & \\
\hline 亲. & 唪 & 疍 & 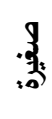 & $\begin{array}{l}\overline{3} \\
3 \\
3\end{array}$ & 㕩: & 录 & 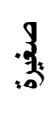 & $\begin{array}{l}\overline{3} \\
\text { s. }\end{array}$ & 管 & 疍 & ). & 承 & 棒 & $\begin{array}{l}3 \\
3 \\
3\end{array}$ & : & \\
\hline 4 & 0 & 0 & 4 & 6 & 3 & 2 & 1 & 3 & 0 & 2 & 1 & 7 & 4 & 3 & 0 & تايمت \\
\hline 1 & 1 & 0 & 0 & 1 & 0 & 0 & 1 & 4 & 0 & 2 & 2 & 4 & 2 & 2 & 0 & دايمونت \\
\hline 8 & 2 & 3 & 3 & 8 & 6 & 2 & 0 & 9 & 2 & 5 & 2 & 7 & 3 & 0 & 4 & ديزاري \\
\hline 6 & 1 & 2 & 3 & 7 & 5 & 2 & 0 & 5 & 0 & 2 & 3 & 5 & 5 & 0 & 0 & عجيبه \\
\hline 4 & 0 & 0 & 4 & 3 & 0 & 2 & 1 & 3 & 0 & 2 & 1 & 6 & 3 & 3 & 0 & لولا \\
\hline 1 & 0 & 0 & 1 & 3 & 0 & 1 & 2 & 3 & 1 & 2 & 0 & 5 & 2 & 2 & 1 & مارفونا \\
\hline 5 & 1 & 2 & 2 & 2 & 1 & 0 & 1 & 3 & 1 & 0 & 2 & 6 & 3 & 1 & 2 & مترال \\
\hline 2 & 1 & 1 & 0 & 5 & 1 & 3 & 1 & 5 & 0 & 4 & 1 & 4 & 1 & 2 & 1 & ميركال \\
\hline
\end{tabular}

صغيرة اقل من 10 ملم، متوسطة بين 9 -11ملم ، كبيرة اكثر من 20 ملم

و (الجدول 5) يوضح نسبة الأوراق المصابة لكل نبات من اصناف البطاطا المختلفة التي لقحت درناتها بالبكتريا المسببة لمرض الساق الأسود حيث وصلت في الصنف لولا الى بورة 30.76\% و 37.78\%و 33.33\% وبمنوسط 29.31\% في النباتات الملقحة بالبكتريا .E.c.a. و و. E.ch.c. على التوالي، عند مقارنتها بمعاملة المقارنة بينما كانت نسبة الأوراق المصابة في

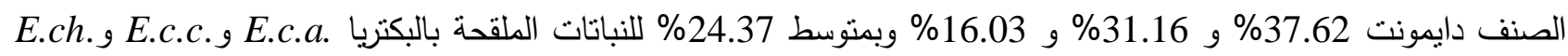

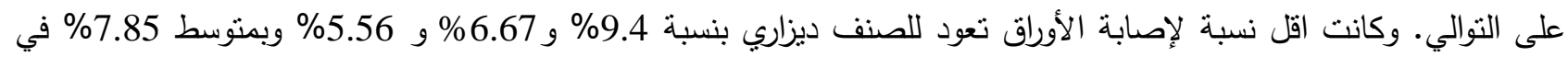

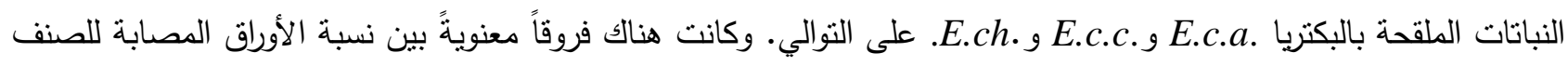
ديزاري والاصناف الاخرى عدا الصنف عجيبة ومترال. وأظهرت نتائج (الجدول 6) نأثثر تلقيح الارنات بالبكتريا تحت ظروف الحقل حيثن حيث أوضحت النتائج زيادة أطوال نباتات الصنف ديزاري الملقحة بالبكتريا E.c.a. حيث وصلت الى 39 سم ومعدل أطوال النباتات لهذا الصنف الملقح نباتها بالبكتريا المسببة لمرض الساق الأسود وصلت الى 31.5 سم بينما كانت أطوال نباتات المقارنة 25 سم فقط. وكانت هناك فروات فروقاً معنويةً بين أطوال نباتات الصنف ديزاري وبقية الأصناف وبين النباتات الملقحة بالبكتريا E.c.a. والمقارنة بالنباتات الملقحة بالبكتريا و E.ch. E.c.c. اذ كان معدل أطوال النباتات المصابة 19.25 سم و 21.33 سم على التوالي بينما كانت أطوال نباتات المقارنة 25 سم و و30 سم على التوالي. وكانت هنالك فروقاً معنوية بين معدل أطوال نباتات الصنف ديزاري الملقحة بالبكتربا وبقية الأصناف الاخرى. وقد أنشار (1994) Burgess et al., الى التأثير الثديد لهذه البكتريا في إنتاجية ونمو نبانات البطاطا. 


$$
\text { زهراء سالم المشهداني و نديم احمد رمضان }
$$

الجدول 5: النسبة المئوية للأولق المصابة في النباتات الناتجة من تلقيح الدرنات بالبكتريا المسببة لمرض الساق الأسود في الحقل

\begin{tabular}{|c|c|c|c|c|c|}
\hline \multirow{2}{*}{ المتوسط } & \multicolumn{3}{|c|}{ البكتريا } & \multirow[t]{2}{*}{ المقارنة } & \multirow[t]{2}{*}{ الصنف } \\
\hline & E.ch. & E.c.c. & E.c.a. & & \\
\hline 18.32ب ج & 15.28 ب -و & 20.83أ- و & 22.19 ب - و & 15.0 ب -و ** & تايمت \\
\hline 24.37 أب & 16.3أ-و & 31.16 - ج & 37.62 & 12.22 ب -و & دايمونت \\
\hline 37.85 & 5.56 & 6.67 هـ & 9.4 د-و & 9.72 د-و & ديزاري \\
\hline 13.83ج د & 13.89ب -و & 21.67 ب -و & 15.0ب -و & 9.77 & عجييه \\
\hline 29.31 & 33.33 أ ب & 37.78 & 30.76 أ - دد & 15.37 ب -و & لولا \\
\hline 21.0 & $9-120.24$ & 21.94 أ-و & , 28.25 & 13.59 ب - و & مارفونا \\
\hline 14.02ج د & 12.5ب-و & 23.33 أ- هـ & 14.17ب -و & 6.1 هـ و & مترال \\
\hline 15.42ب - د & 6.67 هـ و & 11.1ج - و & 23.33 & 20.56 أ- هـ & ميركال \\
\hline- & 15.44 & 21.87 & 22.60 & 12.16 اُ ب & المتوسط \\
\hline
\end{tabular}

*الارقام التي تحمل احرفا متثابهة تدل على عدم وجود فروق معنويه بينها عند مستوى احتمال 0.05 حسب اختبار دنكن افقيا وعموديا. الجدول 6: تأثير تلقيح درنات اصناف البطاطا المختلفة بالبكتريا المسبة لمرض الساق الأسود في طول النباتات المزروعة في

\begin{tabular}{|c|c|c|c|c|c|}
\hline \multirow[b]{2}{*}{ المتوسط } & \multicolumn{3}{|c|}{ البكتريا } & \multirow[b]{2}{*}{ المقارنة } & \multirow[b]{2}{*}{ الصنف } \\
\hline & E.ch. & E.c.c. & E.c.a. & & \\
\hline 22.67 ج دهـ & 26.0 ب ج د - و & 17.67 و ي ع & 26.0 ب ج د هـ و & 12.0د - ي ع *" & تايمت \\
\hline 14.67 و & ت & (12.0 & (15.0 & 17.0 و ي ع & دايمونت \\
\hline 31.50 & 32.0 أ ب ج & 30.0 ب ج د & i 39.0 & 25.0 ب جد-ي & ديزاري \\
\hline 27.0بب & 28.0ب ج د هـ & 31.0 أ-ج & 30.0 ب ج د & 19.0 هـ - ي ع & عجييه \\
\hline 23.0 ب جد & 17.0 و ي ع & 34 0 & ع 15.0 & 28.0 ب ج د هـ & لولا \\
\hline 21.33 ده هـ & 21.0 د- ي & 17.3 وي ع & 17.0 و بي ع & 30.0 ب ج د & مارفونا \\
\hline 19.25 هـ & 16.0 ي ع & 21.0 دـي ع & (15.0 & 25.0 ب ج دو ي & مترال \\
\hline 26.58 ب ج & 25.0 ب ج هـ ي & 30.0 ب جد & 27.0 ب ج د هـ & 24.0 ج دهـ ي & 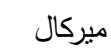 \\
\hline & i22. 46 & 24.13 & أ 23.0 & i 23.67 & المتوسط \\
\hline
\end{tabular}

* الارقام التي تحمل احرفا متشابهة تدل على عدم وجود فروق معنويه بينها عند مستوى احتمال 0.05 حسب اختبار دنكن افقيا وعموديا.

\section{المصادر العربية}

حسن، احمد عبد المنعم (1988). سلسلة العلم و الممارسة في المحاصيل الزراعية. البطاطس الطبعة الاولى. الدار العربية للنشر و

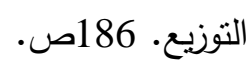
رمضان، نديم احمد رمضان؛ المشهداني، زهراء سالم (2003). دراسة القدرة الامراضية للبكتريا المسببة لمرض الساق الأسود في البطاطا ومقاومتها. مجلة علوم الرافدين. 14 (العدد الثاني خاص بعلوم الحياة)، 164 - 172. رمضان، نديم احمد ؛ المشهداني، زهراء سالم (2006). عزل وتتخيص بكتريا مرض الساق الأسود في البطاطا. مجلة علوم الرافدين. 17 (العدد خاص بعلوم الحياة)، 193 - 203. 
صالح، مصلح محمد سعيد ؛ عبدول، كريم صالح (1988). البطاطا - وإنتاجها خزنها وتصنيعها (الجزء الأول). جامعة صلاح

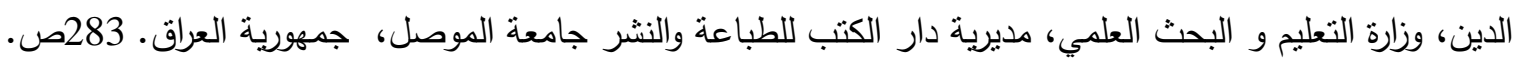

صالح، مصلح محمد سعيد ؛ عبدول، كريم صالح (1988). البطاطا - إنتاجها - خزنها و تصنيعها (الجزء الثاني). جامعة

صلاح الدين، وزارة التعليم و البحث العلمي، مديرية دار الكتب للطباعة والنشر، جامعة الموصل، جمهورية العراق.711

ص

القرغولي، جبار محسن جابر (1999). تأثير البكتربا Pseudomonas fluoresces والمعاملة بكبريتات الكالسيوم على مسببي

مرض التعفن الطري Euratovora var. carotovora caroto ومرض التعفن الجاف Fusarium solani على درنات

$$
\text { البطاطا في الحقل وإثتاء الخزن. اطروحة دكتوراه، كلية الزراعة، جامعة بغداد، العراق. }
$$

المصادر الأجنبية

Anonymous.(1997). Potato / bacterial soft rot and blackleg httpi // www./ pm .cud apis .edu /pmG / $607160 /$ html .1-2.

Burgess, P.J.; Blake man, J.P.; Perombelon, M.C.M. (1994). Contamination and subsequent multiplication of soft rot Erwinia on healthy potato leaves and debris of terhaulm destruction. Plant Pathology. 43, 286 - 299.

Collmer, A.; Keen, N.T. (1986). Therol of pectic enzymes in plant pathogenesis. Ann. Rev. Phytopathol. 24, $283-409$.

DeBoer, S.H.; Verdonck, L.; Vruggink, H.; Harju, P.; Bang, H.O.; Deley, J. (1987). Serological and biochemical variation among potato strains of Erwinia carotovora subspecies atroseptica and their taxonomic relationship to other Erwinia carotovora strains. J. Applied Bacteriology. 63,487- 495 .

Elphinston, J.G. (1987). Soft rot and blackleg of potato, Erwinia spp. Technical information bulletin. 21, 1-18.

Fick, W.; Naumann, K.; Shadow Muller, H.J.; Zielke, R. (1973). Dielebnsdauer von pectobacterium carotovorum var. atrosepticum (vanHall) Dowson auf dempflanzgnt and boden. Arch. Phytopathol. p. Flanzen schutz. 9, 281 -293.

Gudmestad, N.C.; Secor, G.A. (1993). "Management of Soft Rot and Rink Rot". Potato health management. Amer. Phytopathological Society. pp.135-136.

Haag, V. (1997). "Netherlands Catalogs of Potato Varieties". C.P.R.O.D.O, Wageningen NIVAA. 270 p.

Hooker, W.J. (1981). "Compendium of Potato Disease. Amer". Phytopathological Society. 28 p.

Lapwood, D.H.; Read, P.J.; Spokes, J. (1984). Methods for assessing the susceptibility of potato different cultivars to rotting by Erwinia carotovora subspecies atroseptica and carotovora. Plant Pathology. 33,13- 20.

logan, C. (1964). Bacterial hard rot of potato. Europe. Potato J., 7,45- 56.

Morrenhof, J. (1998). "The Road to Seed Potato Production". NIVAA, the Netherlands potato Consultative Institute. pp. 1- 4.

Murray, J.; Fixter, L.M.; Hamilton, I.D.; Peronbelon, M.C.M.; Quinn, C.E.; Graham, D.T. (1990). Serogroups of potato pathogenic Erwinia carotovora strains identify-cations by lipopolysaccharide electrophoretic patterns. J. Applied Bacteriology. 68, $231-240$.

Prokkola, S. (1994). Effect of applying nitrogen fertilizer to a potato seed crop on the susceptibility of the daughter plants to Erwinia carotovora subspecies atroseptica potato Research. 37,103 111.

Smid, E.J.; Jansen, A.H.J.; Gorris, G.M. (1995). Detection of Erwinia carotovora subspecies atroseptica and Erwinia chrysanthemum in potato tubers using polymers chain reaction. Plant Pathology. 44, 1058 - 1069. 